\title{
Adoption of Authenticated Peer-to-Peer Academic Networks - a Case Study of a failure
}

\author{
António Tavares ${ }^{1}$ and Luís Amaral ${ }^{2}$ \\ ${ }^{1}$ Escola Superior de Tecnologia, Instituto Politécnico do Cávado e Ave, Lugar do Aldão , \\ 4750-810 Vila Frescainha S. Martinho BCL, Portugal, ajtavares@ipca.pt \\ ${ }^{2}$ Departamento de Sistemas de Informação, Universidade do Minho, Campus de Azurém , \\ 4800 - 058 Guimarães, Portugal, amaral@dsi.uminho.pt
}

\begin{abstract}
The use of P2P applications in universities has been mainly focused on questions related to file sharing and copyright violation, and little attention has been given to the development of secured and authenticated P2P applications, specially conceived to academic environments. In this paper, we describe Bumerang, an authenticated campus P2P network, which despite technological quality and top level institutional commitment, didn't reach critical mass of users, failing at the individual adoption level. To understand the factors that contributed to this result, we use a holistic approach, considering the process of conception and diffusion and the results from the network activity. We conclude that we must reinforce their perceived utility, deal with the security concerns with new approaches and stay away from using the P2P term.
\end{abstract}

Keywords: peer-to-peer file sharing; authenticated peer-to-peer networks in academic environments; technology adoption; UTAUT; case study.

\section{Introduction}

The core characteristic of the Peer-to-Peer (P2P) technology is the possibility of sharing digital resources - digital contents, processing power, bandwidth and storage - in a free and equal way, amongst the members of a community (peers) in a selfregulated way [1].

Although this technology demonstrated its potential in business and project domains with global impact [2] and maintains a high presence in the global Internet traffic [3], there are still few application domains that have exploited it on a large scale [4]. According to several authors [5,6] the potential of P2P is not wet being met, due to technical and non-technical reasons. The excessive controversy with anonymous $\mathrm{P} 2 \mathrm{P}$ file-sharing networks and copyright violation, maintains the research focus around technological and legal issues [7]. In the case of academic environments, despite the recognized potentialities of $\mathrm{P} 2 \mathrm{P}$ technology and applications [8], these organizations imposed a lot of restrictions to the attempts of exploring them. 
In this paper, we describe our experience with Bumerang, a secure and authenticated P2P campus network. It was developed at the University of Minho, in a unique context of institutional commitment and openness to innovation, which is a rare combination when it comes to $\mathrm{P} 2 \mathrm{P}$. However, against our expectations, and despite the recognized technological quality, the Bumerang network did not reach critical mass of users and resources to be self sustained. It failed at the individual adoption level, hinder the development of its full potential. This result was related to human factors, in the area of Technology Adoption and Diffusion [9, 10]. With the study of this failure, we expect to enrich the knowledge about the factors that contribute to the individual adoption of this kind of P2P networks.

\section{Related Work}

The P2P phenomenon started at the universities with Napster in 1999. Quickly, they was brought to the middle of the digital rights battlefield [11, 12], raising serious problems to the attempts of exploring $\mathrm{P} 2 \mathrm{P}$ potentialities in academic environments. Despite the difficulties, there were a few cases of P2P networks specially conceived and configured to these environments. However, like Bumerang, these projects had a common problem: they had difficulties in acquiring critical mass of users in order to be self sustainable and develop their full potential.

Lionshare was the most visible project in this area, with large resources and institutional support. It had facilities for authenticated P2P collaboration learning among the members of an academic community. The final results indicated that the authentication and access control features wasn't appeal to students, because their perception of P2P was that it was for sharing "any type of files" [13]. At May 2009 Lionshare was discontinued.

The SPIRE project tried to explore Lionshare in the support to informal repositories at the UK academia. Due to technical difficulties and to the believe that "it would be a fruitless effort to attempt to combine the high levels of security necessary to reassure academics and their institutions with the flexible paradigm of P2P" [14], the project team abandoned the Lionshare implementation.

vuCRN [15] was a prototype of an authenticated P2P network for legally information sharing between academics and researchers, imposing authentication and DRM mechanisms. The purpose of the research team was to use file sharing as the beginning of larger P2P network with an unlimited potential for collaboration between academics and researchers.

Finally, regarding empirical studies about individual adoption of authenticated P2P networks in academic environments, as far as we known, Lin et al [16] is the single empirical study available. The study analyzed the use of $\mathrm{P} 2 \mathrm{P}$ network for information sharing in collaborative learning, and concluded that the adoption and use by students was low and was only positively related with subjective norm. This study reinforces the necessity for further work in this area, in order to explore the full potential of P2P in academic environments. 


\section{Bumerang Conception and Diffusion}

Bumerang resulted from the project "P2P Knowledge Sharing" [17], which we started at the end of 2004 , in response to the challenge of built a P2P platform, at the University of Minho, in order to "create and spread a culture of knowledge share between students, teachers and other staff, supported in applications of P2P technology". It's important to note that the central challenge posed to the project, was the exploitation of the P2P technology in an academic environment. Three main goals were defined to the project:

Explore the potentialities of the technology to support communities of knowledge share, regarding formal and informal processes or relations, in the rich social and cultural environment of the academic community;

Explore the potentialities of the technology regarding the possibility of sharing and aggregating resources, with more or less institutional intermediation and control. The idea was to build a scenario where the academic technological infrastructure could be reinforced, with low costs, through a larger P2P network, using resources from individuals (e.g. students) or entities (e.g. schools and departments);

Guarantee the maximum protection of the organization from the potential dangers of the use of this technology.

\subsection{Potential Problems and Solutions}

We wanted to explore a disruptive and problematic technology minimizing the risks for the institution. Hence, the protection of the organization was the main goal of the project, and was addressed considering problems at the legal, technological and social dimensions:

Legal problems - Copyright violation and personal image violation or defamation;

Technological problems - uncontrolled usage of the computational resources and infrastructures; the guarantee of service quality; and external attacks to the network;

Social problems - internal resistances from technical and academic staff related to the negative connotation of $\mathrm{P} 2 \mathrm{P}$, and to the overlapping of functionalities with other services; problems with the University public image, due to the problematic and uncertain external context around $\mathrm{P} 2 \mathrm{P}$, at national and international levels.

To deal with legal problems, a clear legal context was defined to regulate the relation between users and institution, in order to the University defends itself in cases of legal litigations. This was achieved with the definition of the general use terms agreement, together with the guarantee of the identification of the authors of violations, using an institutional authentication process.

The technological problems were approached through control mechanisms, together with a closely relation with the Communications Services (SCOM) - unit responsible for the University network infra-structure. SCOM controlled the authentication of the users and the access to the network from the outside of the University, which was available only through a Virtual Private Network (VPN), slowing the access to the network from outside the University.

Regarding the University public image, we followed an overcautious approach, adopting a low profile and the avoidance of conflicts, in the internal and external 
contexts. This was achieved with a restrictive publicize strategy based essentially in the word of mouth, especially between students, and the availability of the project website restricted to the inside of the University network.

Finally, in order to deal with internal resistances about services overlapping and the lack of some resources, we delivered the growth and sustainability of the system to the participants. This way, we expected that they perceived the utility and potentials of the system and contributed with their own services and resources, adopting a bottom-up process to the growing of the system.

\subsection{Bumerang Concepts and Architecture}

The users participated in the Bumerang network trough communities. A community could be open to all members of the network our closed to a restricted group of members. A user could simultaneously belong to several communities in the system. Fig. 1 shows the global structure of the Bumerang P2P network, based on JXTA technology, whose members were: peers, super-peers and the Bumerang server.

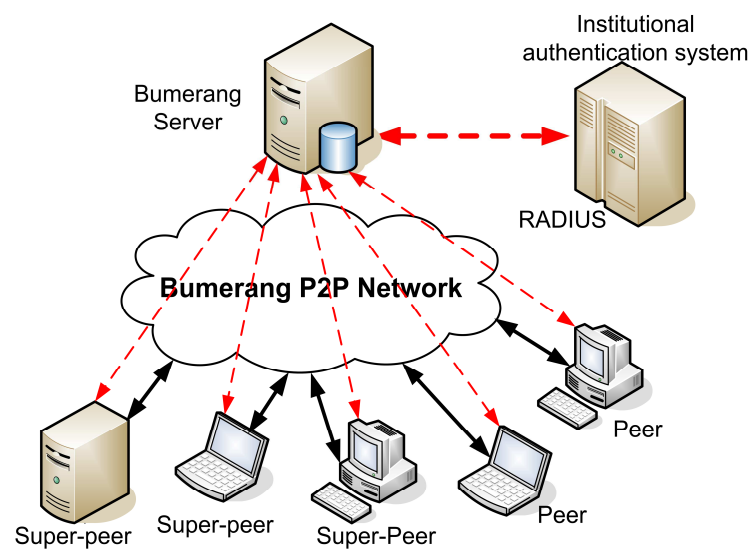

Fig. 1. The Bumerang P2P network: peers, super-peers, and Bumerang server

Bumerang peer was the application used by any peer participating in the network and had to be installed in each machine. It was built with plug-ins, allowing the development of an extensible application for each peer. Because each peer was associated to a user, who participates simultaneously in several communities, a peer could dynamically add plug-ins, according to the requirements and resources of the different communities which the user belonged to.

The user disseminated links inside a community, to the local files he wants to share, using advertisements - messages that contained information about the files (metadata). These were automatically propagated to all members of the community that were online, which could download the files as long as the sharer was online. There were no restrictions to the size of the files. The user could also send instant messages to members of the communities and participate in chats. A plug-in to send 
files directly to another user was available at the end of the first semester of operation of the network.

Bumerang server was the central element in this network. It contained: the databases which audited the system, using the system logs; the tools for the administration and configuration of the system; and the authentication mechanism.

Super-peers were peers with more power and capabilities, used to ensure scalability and performance. A peer could become a super-peer by using a special plug-in. Each community could have its own super-peers which could be fixed or mobile, permanent or temporary.

Community: The concept of community was the way by which the users participated in the Bumerang network and simultaneously was the base of the growth and sustainability of the network.

A community was composed by a set of users that shared a common interest, interacting and sharing knowledge inside it, and gradually defined its own profile, built its own identity and had its own resources. A community could create new services on their own (e.g. plug-ins), having the possibility to provide these services to other communities or to the entire institution. This way, we expected to have a diversity of communities that translated the structure of the academic community in all dimensions - formal and informal.

Persistence: One of the major problems with P2P networks and applications is the volatility of the system, due to the instability of their peers, which are permanently connecting and disconnecting. This brings the problem of resource availability, which increased in the case of Bumerang, because the majority of the peers were portable devices (laptops) connected to the wireless campus network. In Bumerang, despite the predictable system instability, we did not provide a persistence service due to internal resistances from some technical and academic staff.

\section{Bumerang Results}

In order to analyze the Bumerang results, we use a holistic approach, resorting to data triangulation: quantitative data about the network activity; qualitative data about the complex context of the design and implementation of Bumerang, including news and events occurred in the internal or external organizational context; and qualitative data among users and non-users, in order to understand their behaviors and expectations. The analysis is guided by the model of individual adoption of P2P authenticated academic networks [18], presented in section 3.2.

\subsection{Network activity}

We have logs from more than two years of Bumerang activity at the University of Minho, from 23/11/2005 to 9/4/2008. These logs had inconsistencies, caused by the experimental nature of the project. We developed an application which uses 
consistency and consolidation heuristics, and generates a system representing the Bumerang entities (users, files and communities) and their temporal activity, summarized in Table 1. A deep analysis of this data is outside the scope of this paper.

Table 1. Static and Temporal entities

\begin{tabular}{|c|c|c|c|c|}
\hline \multicolumn{2}{|l|}{ Static Entities } & \multirow{2}{*}{$\begin{array}{l}\text { Temporal Entities } \\
\text { Period }\end{array}$} & \multicolumn{2}{|l|}{ Time interval of consecutive... } \\
\hline Users & 397 & & server activity & 64 \\
\hline Files & 3.188 & (betw & iods the system is off or blocked) & \\
\hline Shares & 4.865 & User Session & user activity in the network & 2.821 \\
\hline Downloads & 1.639 & Community Session & community activity & 6.291 \\
\hline Communities & 135 & (at least on & vas connected to the community) & \\
\hline Open & 89 & User Community Session & user activity in a community & 140.296 \\
\hline Closed & 46 & File Community Session & file availability in a community & 4.428 \\
\hline
\end{tabular}

The files detected in the network (3.188) were classified according to Type and UseType. Type was based on the files extension and UseType was based on the use of the file, considering the categories work and entertainment. Work relates to academic activity, and Entertainment includes all the other activities.

The results for UseType are: considering number of files, $22 \%$ to work and $78 \%$ to entertainment; considering size of files, $12 \%$ to work and $88 \%$ to entertainment.

The users of the network were classified according to their gender, position (student, teacher, staff and undefined) and scientific area (Informatics, Engineering, Science, Medicine, Architecture, Management, Law, Social Sciences and Others). The researcher position was included in the staff position.

The results are: Gender (Male 85\%, Female $8 \%$ and Undefined 7\%); Position (Student 93\%, Staff 6\%, Teacher 1\% and Undefined 1\%). Regarding the distribution of users according to area and position, we have some relevant facts: $86 \%$ of students were from Informatics, Engineering or Science; from the group of non-students (29), $28 \%$ (8) were members from the staff of University Documentation Services, which included the Bumerang development team (5). These 8 members were responsible for the major activity of the network.

Temporal activity and Events: The major network activity occurred in the first 4 months, from 23 November 2005 to 28 March 2006. The first significant failure of the system (13 days) occurred during July 2006, which means it was operating 8 months almost uninterrupted, continuing operating uninterrupted until December 2006. After that, its operation had a significant breakdown, with large periods totally disconnected.

There were several events that could affect the individual adoption of the system. The events were: news in the media about P2P litigation and websites closed in Portugal; internal publicizing; and a national award that was given to the project by a Governmental Agency (UMIC) and SUN Microsystems, during November 2006. Apparently, only the last event had some effect on the network activity. The other events occurred after the initial period, when the major network activity occurred, and didn't have effect on the network activity. 


\subsection{Individual Adoption Results}

The model of Individual Adoption of Academic P2P Systems in Fig. 2, is an extension of UTAUT with factors related to: adoption of collaborative technologies, Network Externalities, Social Exchange Theory and Perceived Risk [18]. The findings for the constructs in the adoption model are described next.

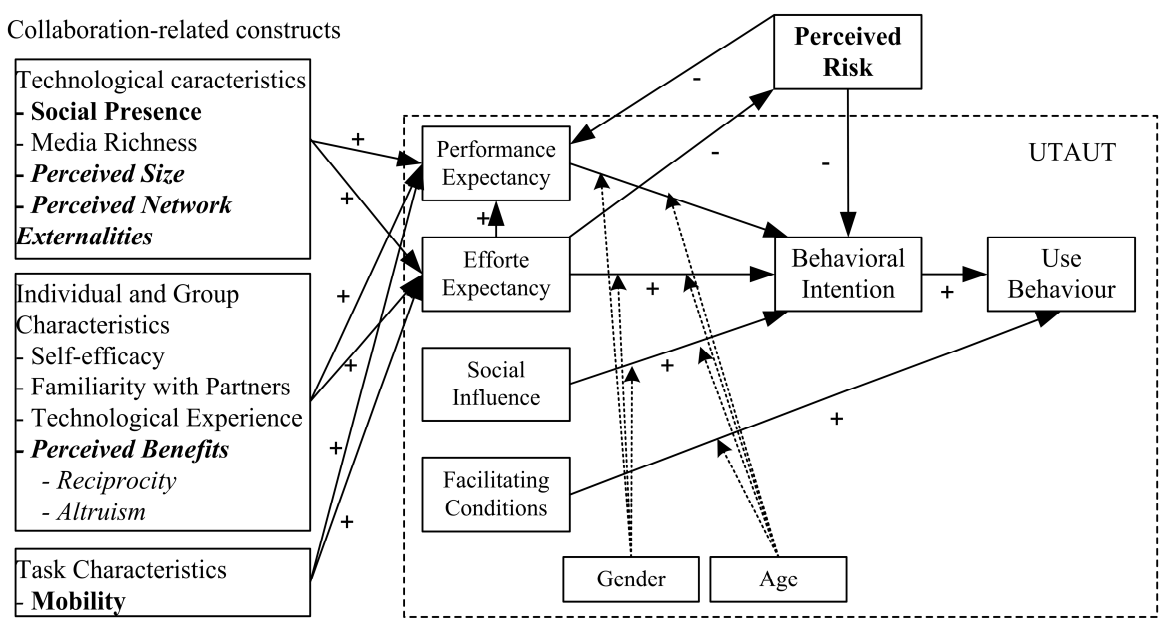

Fig. 2. Individual Adoption of $\mathrm{P} 2 \mathrm{P}$ authenticated academic networks

Performance Expectancy: Performance expectancy relates to how well individuals believe the Bumerang helped them to perform their academic activities, and has the strongest influence on the individual intention of using the system. In the interviews the distribution of very large files and the spontaneous distribution of files in a community, were considered useful.

However, the interviewed pointed the useless of the Bumerang network to the exchange of files for academic activities, considering the existing alternatives. Regarding the distribution of very large files, it was pointed that was rarely used. All the interviewed associated P2P mainly with piracy and copyright violations in anonymous P2P file sharing networks.

Based on the classification of files by useType and the size of files, we can validate the above results. The use of the network to support work activities gives a more precise measure of the construct Performance Expectancy. The network data indicates that the system was used mainly to exchange entertainment material. The files related to work represent $12 \%$ of the total files considering size, and $22 \%$ considering the number of files. About the exchange of large files related to work activities, only 10 files with size larger than $50 \mathrm{MB}$ were exchanged. Considering the files exchanged in communities, the results indicate that from a total of 135 communities, none was used mainly to work activities. 
Effort Expectancy: Effort expectancy relates to how the users found the Bumerang easy to use. All the interviewed considered Bumerang easy to use and intuitive. This was according with the very few messages asking help to the support staff. The major problems were related to the authentication process and the use of VPN to access from the outside of the University.

Social Influence: Social Influence relates to the extent to which an individual perceives that it is important others think that he should use the system, in other words, how the use of Bumerang will affect their image or please their supervisor or co-workers. Based on logs and interviews, we have no evidences related to these construct. In academic environments, this construct is generally relevant in scenarios where the instructor plays a critical role in motivating students to use of the technology. Considering our data, we only had 6 teachers using the system for a short period of time.

Facilitating Conditions: Facilitating conditions relates to the extent to which an individual perceives the availability of organizational and technical resources to support the use of the system. The majority of interviewed recognized that Bumerang had a good technical support.

The technical staff was very responsiveness to the problems reported by users, however, we must considerer two distinct periods:

- From start to December 2006, the project had permanent technical support, with small periods of inactivity occurring during weekends or holydays;

- After December 2006, the project team ended, and the permanent technical support ceased, causing a stop of 2 months, followed by other large stop periods.

When the award from a Governmental Agency (UMIC) and SUN was announced (during November 2006), a new slight activity appeared, interrupted by Christmas holidays. In the reopen of the academic activities (January) the network remained closed, without technical support, which promoted the final breath of the system.

Perceived Risk: Perceived Risk relates to the individual perception about losses and damages in using the system. This can be measure by the identification of profiles of users and communities, according to the type of files they exchanged. But, we have no means to verify copyright violation, and there was no report of abuses or defamation, however, the interviewed reported lawsuits as a significant perceived risk.

Technological characteristics: Social Presence relates to the individual perception about capacities of the technology in transmitting the presence of the other users in the system. In Bumerang, all users were visible and represented by an icon, with two stages: online or offline.

Perceived size of the system relates to the individual perception about the size of the system, regarding the number of files available and the number of active users. According to the interviews, this construct had a strong influence on the perceived usefulness of the system - "When I connected there wasn't anyone there". The large 
number of small user sessions, without any exchanged files, reinforces this result.

Perceived Network Externalities relates to the individual perception about the influence that the size of the system has on its potential benefits. The results are the same as for Perceived size.

Individual and Group characteristics: The constructs related to collaboration technology: experience with a particular technology (Technology Experience); perceived self-efficacy in using the technology (Self-efficacy); and the familiarity with the communication partners (Familiarity with Partners), can be measure by the user's profiles according to area.

We have a total of $90 \%$ of users from the areas of Informatics, Engineering and Science, indicating a high level of technology experience and self-efficacy.

Task characteristics: Regarding task characteristics, mobility is related to the extent the user tasks require that he must be outside the work environment [19], in this case, the University network.

The mobility in Bumerang was limited to the IP address of the University, due to security concerns. The only way to access the network from the outside of the University was by using a VPN, which slowed and difficult the use of Bumerang outside of the University. According to the interviews, this construct had a strong influence on the perceived usefulness of the system - "I couldn't work with it at home, this way I couldn't rely on it to my work".

\section{Conclusion}

In this paper, we have presented Bumerang, a secured and authenticated P2P campus network, and described the complex process of its design and implementation, which includes technological, legal and social constraints, together with the results from the network activity.

Against our expectations, the network did not reach critical mass to be self sustained, failing at the individual adoption level. The presented results indicate that the users didn't consider the system useful to their academic activities, associating P2P with sharing files related to entertainment activities. A security mechanism like VPN, was considered a strong limitation to mobility, and consequently, to the utility of the system.

Concluding, in order to explore the potential of authenticated P2P networks in academic environments, we must reinforce their perceived utility and deal with the security concerns with new approaches. We must also stay away from using the P2P term, which is poisoned by the anonymous file-sharing networks and copyright concerns, affecting the perceived utility. We must describe P2P in a different way, like file back-up and synchronization or cloud computing, which is been made by a new generation of P2P tools and services, like LiveMesh and Dropbox. The comparison of Bumerang results with the results obtained with these new tools, in 
academic scenarios, will give more insights in the individual adoption of authenticated P2P networks in academic scenarios.

\section{References}

1. Steinmetz, R., Wehrle, K.: Peer-to-peer systems and applications. Springer, Berlin;New York (2005)

2. Anderson, D.P., Cobb, J., Korpela, E., Lebofsky, M., Werthimer, D.: SETI@home - An experiment in public-resource computing. Commun. ACM 45 (2002) 56-61

3. Singel, R.: Peer-to-Peer Passé, Report Finds. Wired magazine (2009)

4. Walkerdine, J., Hughes, D., Rayson, P., Simms, J., Gilleade, K., Mariani, J., Sommerville, I.: A framework for P2P application development. Computer Communications 31 (2008) 387-401

5. Sigurdsson, H.M., Halldorsson, U.R., Hasslinger, G.: Potentials and challenges of peer-topeer based content distribution. Telematics and Informatics 24 (2007) 348-365

6. Hughes, J., Lang, K.R., Vragov, R.: An analytical framework for evaluating peer-to-peer business models. Electronic Commerce Research and Applications 7 (2008) 105-118

7. Nagaraja, K., Rollins, S., Khambatti, M.: Looking beyond the Legacy of Napster and Gnutella. IEEE DISTRIBUTED SYSTEMS ONLINE 7 (2006)

8. ONU: UN Recommendation in favour of P2P in Science. In: Information, C.S.T.W.G.o.S. (ed.). Civil Society Science Information Working Group, 2004 (2004)

9. Davis, F.D.: Perceived Usefulness, Perceived Ease Of Use, And User Acceptance Of Information Technology. Mis Quarterly 13 (1989) 319-340

10.Venkatesh, V., Morris, M.G., Davis, G.B., Davis, F.D.: User acceptance of information technology: Toward a unified view. Mis Quarterly 27 (2003) 425-478

11.Ennis, D., Anchan, D., Pegah, M.: The front line battle against P2P. Proceedings of the 32nd annual ACM SIGUCCS conference on User services. ACM, Baltimore, MD, USA (2004) $101-106$

12.Putter, J.: Copyright Infringement v. Academic Freedom on the Internet: Dealing with Infringing Use of Peer-to-Peer Technology on Campus Networks. Journal of Law and Policy 14 (2006) 419

13.Halm, M.: LionShare: Connecting and Extending Peer-to-Peer Networks (Final Report). Pennsylvania State University, 2006 (2006)

14.White, D.: LionShare in the UK: 'technical and political pros and cons'. In: (JISC), P.S.d.J.J.I.S.C. (ed.): (2006)

15.Zhang, Y.C., Shi, H., Wang, X., Zhang, J.Y.: Collaborative legal information sharing on P2P network. 2007 Ifip International Conference on Network and Parallel Computing Workshops, Proceedings (2007) 41-47

16.Lin, F., Lin, S., Wang, Y.: Can Peer-to-Peer Networks Facilitate Information Sharing in Collaborative Learning? Hawaii International Conference on System Sciences, Proceedings of the 41st Annual (2008) 5-5

17.Tavares, A.: Partilha de Conhecimento p2p. Universidade do Minho, Braga, Portugal (2004)

18.Tavares, A.: Como usar redes P2P autenticadas em contexto académico? : $8^{\mathrm{a}}$ Conferência da Associação Portuguesa de Sistemas de Informação, Setubal (2008)

19.Dennis, A., Venkatesh, V., Venkatraman, R.: Adoption of Collaboration Technologies: Integrating Technology Acceptance and Collaboration Technology Research. Working paper, TR-142-1, Information Systems Department, Indiana University (2004) 